\title{
Modified Rate Law for Bimolecular Reactions: Applicable to Surface as well as Non-surface Reactions
}

\author{
GAMI GIRISHKUMAR BHAGAVANBHAI ${ }^{1}$ and RAWESH KUMAR ${ }^{2 *}$ \\ 'Department of Chemistry, Sankalchand Patel University, Gujarat, India. \\ ${ }^{2}$ Department of Chemistry, Indus University, Ahmedabad, India. \\ *Corresponding author E-mail: kr.rawesh@gmail.com
}

http://dx.doi.org/10.13005/ojc/370622

(Received: July 12, 2021; Accepted: December 15, 2021)

\begin{abstract}
The rate equations in kinematics are expressed through basic laws under surface reaction as well as non-surface reaction. Rate law is center theme of non-surface reaction whereas Langmuir adsorption isotherms are basis of surface reaction rate expressions. A modified rate equation for bimolecular reaction is presented which considers both catalyst surface affairs as well as fraction of successful collision of different reactant for cracking and forming bonds. The modified rate law for bimolecular reaction for surface as well as non-surface reaction is stated as "Rate of a reaction is directly proportional to concentration as well as catalyst surface affair of each reactant" as $r=k$ $\Omega_{A}[A] \Omega_{B}[B]$ where catalyst surface affair of $\mathrm{i}^{\text {th }}$ species is defined as $\Omega_{i}=K_{i} /\left(1+K_{i}[i]+K_{i}[j]+\ldots\right)$. Here, $\mathrm{K}_{\mathrm{i}} \mathrm{i}$ is the equilibrium constant of "i" species for adsorption-desorption processes over catalyst. $\mathrm{i}, \mathrm{j}, \ldots$ indicates the different adsorbed chemical species at uniform catalyst sites and the same [i], [j],... indicates the concentration of different adsorbed chemical species at uniform catalyst sites.
\end{abstract}

Keyword: Surface Reaction, Non-surface reaction, Modified Rate law, Bimolecular reaction, Catalyst surface affair.

\section{INTRODUCTION}

The rate law is the center of all rate expressions for non-surface reactions. The core of the rate law is embedded in kinetic theory of collisions with the assumption that fraction of collisions having enough energy leads molecular vibration and thereafter breaking/forming of new bonds ${ }^{1}$. Simply for a second order reaction, rate is directly proportional to different concentration of reactants.

$$
\begin{aligned}
& \mathbf{A}+\mathbf{B} \stackrel{k}{\longrightarrow} \mathbf{C} \\
& \mathrm{r}=\mathrm{k}[\mathrm{A}][\mathrm{B}]
\end{aligned}
$$

If surface reactions are included, the rate of reaction can be broadly assigned as interaction between two adsorbed chemical species (on catalyst surface) or interaction between adsorbed species (on catalyst) and non-adsorbed species (expressed in term of concentration/pressure) or interaction between non-adsorbed species in the reaction mixture. For the first case, interaction between the two adsorbed species can be shown by product of surface coverage of both different species over the catalyst surface as shown in Scheme 1(1). For second case, interaction between one adsorbed and one non-adsorbed species can be shown by product of

This is an Open Access article licensed under a Creative Commons license: Attribution 4.0 International (CC- BY). Published by Oriental Scientific Publishing Company @ 2018

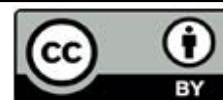


surface coverage of one species over the catalyst site and concentration of another species in the reaction mixture as shown in Scheme 1(2). For third case, interaction between non-adsorbed species can be viewed by product of concentration of both species and very likely as rate law discussed in right hand side expression of Scheme 1(3) as well as in eq (1).

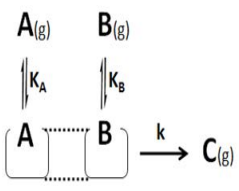

(1)

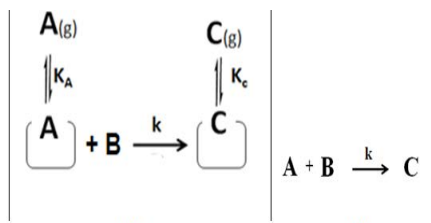

(2)

(3)
Scheme 1. (1) The adsorbed "A" and adsorbed "B" undergoes into a reaction (2) The adsorbed " $A$ " undergoes into a reaction with non-adsorbed "B" (3) Two nonadsorbed " $A$ " and " $B$ " undergo into a reaction.

$\mathrm{r}=\mathrm{k} \theta_{\mathrm{A}} \theta_{\mathrm{B}}$

$\mathrm{r}=\mathrm{k} \theta_{\mathrm{A}}[\mathrm{B}]$

$r=k[A][B]$

The first case or Scheme 1 (1) shows purely surface reaction and it should be dealt with Langmuir adsorption isotherms ${ }^{2,3}$ First of all reactants "A" and " $\mathrm{B}$ " are adsorbed on uniform catalyst surface having $\mathrm{K}_{A}$ and $\mathrm{K}_{B}$ equilibrium constant of adsorptiondesorption respectively. Further both adsorbed species interact and undergoes into a reaction having rate constant " $\mathrm{k}$ " as shown in scheme 1 (1). The surface coverage of each reactant can be derived by solving the equation of rate of adsorption $\left(v_{a}\right)$ as well rate of desorption $\left(v_{d}\right)$ which are reversible to each other. The rate of adsorption of a species is proportional to the concentration/pressure of species in the liquid/gas phase respectively as well as fractional of the surface that is bare/ uncovered $\left(\theta_{0}\right)$. The total catalytic active sites are $1\left(1=\right.$ fraction of surface uncovered $\left(\theta_{0}\right)+$ fraction of surface covered ( $\theta_{\text {reaction species }}$ ) by each species). So, overall rate of adsorption of species $A$ and $B$ can be expressed as equation $5 \& 7$ respectively. Again the rate of desorption is proportional to fraction of surface covered ( $\left.\theta_{\text {reaction species }}\right)$ by adsorbed species as equation $6 \& 8$.

$v_{a}^{A}=k_{a}[A]\left(1-\theta_{A}-\theta_{B}\right)$

$\mathrm{v}_{\mathrm{d}}^{\mathrm{A}}=\mathrm{k}_{\mathrm{d}} \theta_{\mathrm{A}}$
$v_{a}^{B}=k_{a}[B]\left(1-\theta_{A}-\theta_{B}\right)$

$v_{d}^{B}=k_{d} \theta_{B}$

As adsorption and desorption are reversible processes, equilibrium constant comes in existence. Further equations (5-8) are solved and two equations having two unknown $\left(\theta_{A}\right.$ and $\left.\theta_{B}\right)$ are derived and solved. Finally, value of $\theta_{A}$ and $\theta_{B}$ can be put in eq (1) and then rate equation becomes as

$r=k_{A}[A] K_{B}[B] /\left(1+K_{A}[A]+K_{B}[B]\right)^{2}$

Overall the calculation of surface coverage needs the idea of many adsorption deadsorption expressions and its solutions. As well as surface conditions vary, solutions of equation becomes tougher i.e. the product " $\mathrm{C}$ " may also initiate reversible reaction, reactant may adsorbed nonequivalent surfaces of the catalyst etc. So, it is needed to present some law which is simpler as rate law as well as which can satisfy both surface and non-surface reactions. Herein, a modified rate law applicable to convention as well as surface reaction is proposed.

\section{Modified rate law for surface and non-surface reaction}

The equation (9) can be explained in three parts as mentioned below;

$\mathrm{r}=(\mathrm{k}) .\left(\frac{K_{A}}{1+K_{A}[A]+K_{A}[B]}\right)\left(\frac{K_{B}}{1+K_{A}[A]+K_{A}[B]}\right) \cdot([\mathrm{A}][\mathrm{B}])$
It should be noted that first part "rate constant", second part is expressions related to "surface adsorption and surface deadsorption phenomena of reactant A and B" and third part "product of reactants concentration" remain intact as rate law. We termed the second section as surface affairs of reactant $A$ (termed as $\Omega_{A}$ ) and surface affairs of reactant $B$ (termed as $\Omega_{B}$ ) respectively. So, now the above expression can be written as

$$
\begin{aligned}
& r=(k) \cdot \Omega_{A} \Omega_{B} \cdot([A][B]) \\
& r=k \Omega_{A}[A] \Omega_{B}[B]
\end{aligned}
$$

So, the modified rate law for bimolecular reaction over (applicable to surface and non-surface reaction) can be stated as "Rate of a reaction is directly proportional to concentration as well as catalyst surface affair of each reactant". Where catalyst surface affair $(\Omega)$ of " $i$ "th" species is defined as 
$\left.\Omega_{\mathrm{i}}=\mathrm{K}_{\mathrm{i}} /\left(1+\mathrm{K}_{\mathrm{i}}[\mathrm{i}]+\mathrm{K}_{\mathrm{i}} \mathrm{i}\right]+\ldots\right)$

Where $\mathrm{K}_{\mathrm{i}}$ is the equilibrium constant of "i" species for adsorption-desorption processes over catalyst. i, j, k,... indicates the different adsorbed chemical species at uniform catalyst sites and the same [i], [j], [k],... indicates the concentration of different adsorbed chemical species at uniform catalyst sites. So in the catalyst surface affairs of one species, there will be contributions of another species also which are adsorbed on uniform catalyst sites (as "i" and "j" species are adsorbed on metal atom sites of catalyst).

The equation (11) can be presented as described below.

$$
\begin{aligned}
& \Omega_{\text {perticular species }}=\frac{\text { Equilibrium constant of the perticular species }}{1+(\text { Sum of products of Equilibrium constant and concentration of each }} \\
& \text { adsorbed species at uniform catalyst sites) }
\end{aligned}
$$

So, for a reaction pattern where reactants $A$ and $B$ are adsorbed on uniform catalyst surface (Langmuir-Hinshelwood uniform surface,) and then adsorbed species undergo for a reaction and liberates product $\mathrm{C}$ as presented below.

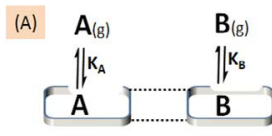
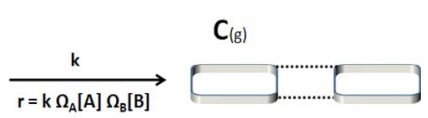

(B)

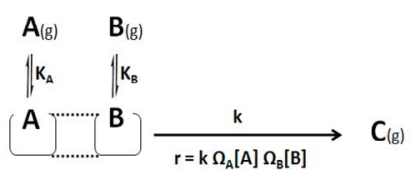

Fig. 1. (A) Scheme of reaction: $A$ and $B$ in gas phase interact with the surface and then undergoes a reaction which yields in product C. (B) Quick presentation of Scheme of reaction

Then catalyst surface affairs of $A$ and $B$ species are defined as

$\Omega_{A}=K_{A} /\left(1+K_{A}[A]+K_{B}[B]\right)$

$\Omega_{B}=K_{B} /\left(1+K_{A}[A]+K_{B}[B]\right)$

So, rate of surface reaction can be found by putting equation 12 and 13 in modified rate equation, $r=k \Omega_{A}[A] \Omega_{B}[B]$

$r=k\left(\frac{K_{A}}{\left(1+K_{A}[A]+K_{B}[B]\right)}\right)[A]\left(\frac{K_{B}}{\left(1+K_{A}[A]+K_{B}[B]\right)}\right)[B]$

$r=\mathrm{kK}_{\mathrm{A}}[\mathrm{A}] \mathrm{K}_{\mathrm{B}}[\mathrm{B}] /\left(1+\mathrm{K}_{\mathrm{A}}[\mathrm{A}]+\mathrm{K}_{\mathrm{B}}[\mathrm{B}]\right)^{2}$

Synthesis of ammonia by $\mathrm{N}_{2}$ and $\mathrm{H}_{2}$ over $\mathrm{Fe}_{2} \mathrm{O}_{3}$ catalyst is the simplest example of LangmuirHinshelwood uniform surface reaction. $\mathrm{H}_{2}$ and $\mathrm{N}_{2}$ are adsorbed dissociately over catalyst surface and then adsorbed atomic species "H" and "N" undergo reaction and liberate ammonia.
Case I. If product (C) will form and subsequently $C$ interacts with the catalyst surface having adsorption phenomena. Then catalyst surface affair of reactant $A$ and $B$ are modified as below.

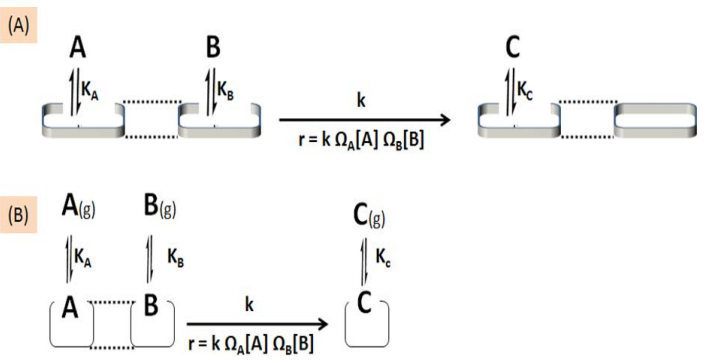

Fig. 2. (A) Scheme of reaction: $A$ and $B$ in gas phase interact with the surface and then undergoes a reaction which yields in product $C$. $C$ again undergoes adsorptiondeadsorption interaction with catalyst surface (B) Quick presentation of Scheme of reaction

$\Omega_{A}=K_{A} /\left(1+K_{A}[A]+K_{B}[B]+K_{C}[C]\right)$

$\Omega_{B}=K_{B} /\left(1+K_{A}[A]+K_{B}[B]+K_{C}[C]\right)$

So, rate of surface reaction can be finding by putting equation 15 and 16 modified rate equation,

$r=k \Omega_{A}[A] \Omega_{B}[B]$

$r=k\left(\frac{K_{A}}{\left(1+K_{A}[A]+K_{B}[B]+K_{C}[C]\right)}\right)[A]\left(\frac{K_{B}}{\left(1+K_{A}[A]+K_{B}[B]+K_{C}[C]\right)}\right)[B]$

$r=k_{A}[A] K_{B}[B] /\left(1+K_{A}[A]+K_{B}[B]+K_{C}[C]\right)^{2}$

Case II. If product $(C)$ will be adsorbed on uniform catalyst sites and further involve in reverse reaction. This time not only catalyst surface affairs of reactant $A$ and $B$ will be modified but also new affairs of $C$ with catalyst surface should also be considered. The rate of reaction can be expressed as below:

$r=k_{1} \Omega_{A}[A] \Omega_{B}[B]-k_{-1} \Omega_{C}[C]$ 

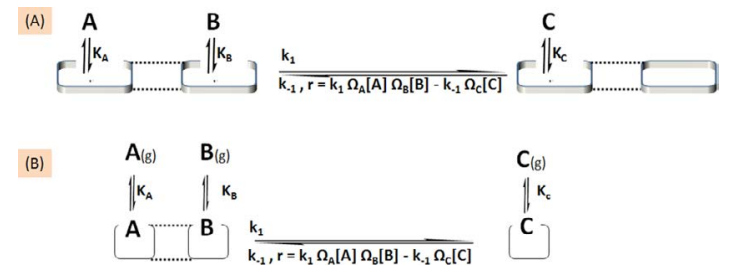

$\Omega_{A}=K_{A} /\left(1+K_{A}[A]+K_{B}[B]+K_{C}[C]\right)$

$\Omega_{B}=K_{B} /\left(1+K_{A}[A]+K_{B}[B]+K_{C}[C]\right)$

$\Omega_{C}=K_{C} /\left(1+K_{A}[A]+K_{B}[B]+K_{C}[C]\right)$

So, rate of surface reaction can be found by putting equation 19-21 into equation 18 .

$r=\left\{k_{1} K_{A}[A] K_{B}[B] /\left(1+K_{A}[A]+K_{B}[B]+K_{C}[C]\right)^{2}\right\}-\left\{k_{-1}\right.$ $\left.\mathrm{K}_{\mathrm{C}}[\mathrm{C}] /\left(1+\mathrm{K}_{\mathrm{A}}[\mathrm{A}]+\mathrm{K}_{\mathrm{B}}[\mathrm{B}]+\mathrm{K}_{\mathrm{C}}[\mathrm{C}]\right)^{2}\right\}$

Case III. If a reactant (say $B$ ) from the gas/ solution reacts with an adsorbed reactant (say $A$ ) without adsorbing itself on the surface as in EleyRideal process ${ }^{6}$. This time non-adsorbed reactant (B) had no surface affairs on catalyst surface and so catalyst surface affairs of non-adsorbed reactant (B) should be removed from equation 10. Then the new rate expression will be as below:

$r=k \Omega_{A}[A][B]$

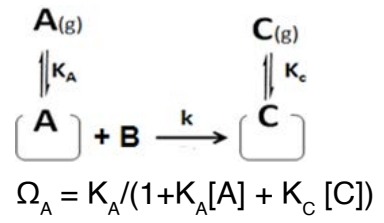

So, rate of surface reaction can be found by putting eq (24) into eq. (23).

$r=k_{A}[A][B] /\left(1+K_{A}[A]+K_{C}[C]\right)$

Hydrogenation of gaseous ethylene molecule by adsorbed hydrogen over Ni surface ${ }^{7}$, The esterification of "chemosorbed 1-hexene" with "heptanoic acid in bulk" over Amberlyst catalyst ${ }^{8}$ and the dimerization of chemisorbed alkene C8 and C24 linear alkenes in liquid phase over Amberlyst catalyst follow Eley-Rideal kinetics ${ }^{9}$.

Case IV. Another possibility may be that reactants ( $A$ and $B$ ) adsorbed on non-uniform surfaces of the catalyst (respect to each other catalyst sites) or adsorbed at different sites of catalyst in close proximity (Langmuir-Hinshelwood non-uniform surface). Here, at one uniform catalyst surface only one species is adsorbed. So, in the catalyst surface affairs of one species, there will be no participation of another species which is adsorbed on different sites/non-uniform sites. The parts of catalyst which adsorb "i" species are different from those which adsorb "j" species.

The rate of reaction can be expressed as below:

$r=k \Omega_{A}[A] \Omega_{B}[B]$

A B

$\left\|\mathrm{K}_{\mathrm{A}} \quad\right\| \mathrm{K}_{\mathrm{B}}$

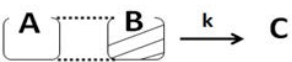

$\Omega_{\mathrm{A}}=\mathrm{K}_{\mathrm{A}} /\left(1+\mathrm{K}_{\mathrm{A}}[\mathrm{A}]\right)$

$\Omega_{\mathrm{B}}=\mathrm{K}_{\mathrm{B}} /\left(1+\mathrm{K}_{\mathrm{B}}[\mathrm{B}]\right)$

So, rate of surface reaction can be found by putting eq (27 \& 28) into eq. (26)

$r=\mathrm{kK}_{\mathrm{A}} \mathrm{K}_{\mathrm{B}}[\mathrm{A}][\mathrm{B}] /\left\{\left(1+\mathrm{K}_{\mathrm{A}}[\mathrm{A}]\right)\left(1+\mathrm{K}_{\mathrm{B}}[\mathrm{B}]\right)\right\}$

The reaction between hydrogen and nitrous oxide on gold ${ }^{10}$ and reaction between hydrogen and carbon dioxide on tungsten ${ }^{11}$ are examples of such kinetics. Two gases $\mathrm{H}_{2}$ and $\mathrm{N}_{2} \mathrm{O}$ are adsorbed independently over gold, they react and form $\mathrm{H}_{2} \mathrm{O}$ and $\mathrm{N}_{2}$. In the same way, two gases $\mathrm{H}_{2}$ and $\mathrm{CO}_{2}$ are adsorbed independently over tungsten, they react and form $\mathrm{H}_{2} \mathrm{O}$ and $\mathrm{CO}$.

Case V. If neither's of reactants have catalyst surface affair or both reactants are simply interacting and finally gives the product $\mathrm{C}$. Then, catalyst surface affairs of reactants $A$ and $B$ should be removed from equation 10 . This time, the rate of reaction is same as rate law for second order reaction as equation (1).

$$
\begin{aligned}
& \mathbf{A}+\mathbf{B} \stackrel{\mathbf{k}}{\longrightarrow} \mathbf{C} \\
& r=k[A][B]
\end{aligned}
$$

\section{CONCLUSION}

It can be concluded that the modified rate law for bimolecular reaction is easier and equally applicable to both surface reaction and non-surface reaction. Along with normal non-surface reaction, 
all the case of surface reaction based on LangmuirHinshelwood uniform surface treatment, Eley-Rideal and Langmuir-Hinshelwood non-uniform surface treatment can be derived easily within couple of steps.

\section{ACKNOWLEDGEMENT}

G. G. Bhagavanbhai acknowledges Administration of Sankalchand Patel University
Gujarat, India for providing continuous research support. Rawesh Kumar acknowledges the R\&D section of Indus University, Ahmedabad, India for supporting research.

\section{Conflict of Interest}

The authors declare that they have no known financial interests with the work reported in this paper.

\section{REFERENCES}

1. Harteck, P.; Zeitschrift für Physikalische Chemie., 1928, 139, 98-106.

2. Langmuir, I. Journal of the American Chemical Society., 1916, 38, 2221-2295.

3. Langmuir, I. Journal of the American Chemical Society., 1918, 40, 1361-1403.

4. Langmuir, I. Transactions of the Faraday Society., 1922, 17, 621-654.

5. Hinshelwood, C. N. Clarendon Press, Oxford, England., 1926, 145.

6. Rideal, E. K. Proceedings of the Cambridge Philosophical Society., 1939, 35, 130; Eley D. D.; Rideal, E. K. Proceedings of the Royal Society of London. Series A., 1941, 178, 429-451.

7. Rideal, E. K. XXXIX. Journal of the Chemical
Society., 1922, 121, 309-318.

8. Gee, J.C; Fisher, S. Journal of Catalysis., 2015, 331, 13-24.

9. Gee, J. C; Williams, S. T. Dimerization of linear olefins on Amberlyst ${ }^{\circledR}$ 15: Effects of chain length and double-bond position. Journal of Catalysis., 2013, 303, 1-8.

10. Hutchison, W. K.; Hinshelwood, C. N. CCl. The interaction of hydrogen and nitrous oxide on the surface of gold. Journal of the Chemical Society., 1926, 129, 1556-1559.

11. Hinshelwood, C. N.; Prichard C. R. CCVI. The interaction of carbon dioxide and hydrogen on the surface of tungsten. J. Chem. Soc., Trans., 1925, 127, 1546-1552. 